\title{
POLÍTICA, FORÇA E VIRTÙ EM MAQUIAVEL
}

\author{
Paulo H.S Costa ${ }^{1}$ \\ Universidade Federal de Minas Gerais (UFMG) \\ (D) https://orcid.org/0000-0002-4389-6893
}

\section{RESUMO:}

Nosso objetivo, neste texto, será demonstrar que a noção de força (que aparece não explicitamente no Príncipe de Maquiavel, nos contextos de conquista-conservação e fundação-conservação), é, na verdade, uma noção de como a força pode ser tratada como uma atividade política. Nosso objetivo, nesse sentido, será demonstrar que, enquanto atividade política: (1) força está amparada em diferentes possibilidades de uso e, principalmente, que (2) força, no Príncipe, pode ser concebida como um exercício de virtù.

PALAVRAS-CHAVE: Política; Conquista; Conservação; Virtù; Força.

\section{POLICY, FORCE AND VIRTÙ IN MACHIAVELLI}

\begin{abstract}
:
Our aim, in this text, is to show that the notion of force (which does not appear explicitly in the Prince of Machiavelli, in the contexts of conquestconservation and foundation-conservation), is, actually, a sense of how the force can be treated as political activity. Our aim, in this regard, is to show that while political activity: (1) force is supported by different possibilities of use and, mainly, that (2) force, in the Prince, can be conceived as a virtù exercise.
\end{abstract}

KEYWORDS: Policy; Conquest; Conservation; Virtù; Force.

\section{Contexto Político do Príncipe}

Maquiavel inicia a obra $O$ Príncipe com uma classificação das formas políticas em duas categorias, a saber, os principados e as repúblicas ${ }^{2}$.

\footnotetext{
${ }^{1}$ Mestrando em Filosofia pela Universidade Federal de Minas Gerais (UFMG), Minas Gerais - Brasil. E-mail: paulohscostabicalho@gmail.com.

2 José Ames (2002) destaca dois pontos importantes para a separação realizada por Maquiavel. O primeiro ponto é que Maquiavel deixa de lado "não só a multiplicidade das
} 
Ao longo da obra, de modo geral, Maquiavel vai indicando ${ }^{3}$ como deveria ser a ação política de um príncipe na gestão de novos principados ${ }^{4}$. Contudo, é importante dizer que o termo deveria ${ }^{5}$ utilizado aqui, não pode ser entendido como uma condição normativa ${ }^{6}$. Maquiavel, diferentemente de uma tradição normativa (que, em política, se reporta a Platão e Aristóteles e, especialmente, à pergunta sobre um governo ou governante ideal), pretende apenas descrever como os homens de seu tempo governam ${ }^{7}$. Para isso ele recorre à história e ao contexto italiano ${ }^{8}$ (BIGNOTTO, 1991, pp.193-194). Embora o contexto histórico de Maquiavel no Príncipe seja extenso e complexo ${ }^{9}$, podemos, ainda assim, apresentá-lo a partir de dois pontos: (a) pelo contexto político da Itália e, (b) pelo papel político da Igreja.

formas" (p. 178) políticas apontadas pela tradição, como também deixa de lado "considerações sobre a natureza do Estado" (ibidem); o segundo ponto é que Maquiavel reconhece com esta divisão que não existe separação entre "governos legítimos e ilegítimos" (ibidem). Assim, "o príncipe antigo (hereditário) apenas tem o privilégio de explorar o sucesso obtido outrora na luta por um príncipe novo (usurpador). Um não é mais legítimo do que outro, pois também o principado hereditário foi no seu começo o resultado da usurpação de um poder legítimo. Assim, a verdadeira questão se transfere daquela consagrada pela tradição, de distinguir entre governos legítimos e ilegítimos, para a da conquista, fundação e manutenção do domínio. Para tanto, o exame dos "principados novos' é o mais indicado e, por isso, sua análise vai centra-se neles" (ibidem).

${ }^{3}$ Harvey C. Mansfield (1996) diz que: "So The Prince, with its political advice to an active politician that politics should not be limited by anything not political" (p. 176). O que Mansfield chama de "political advice" parece apontar para o fato de que a obra não é um manual da atividade política dos príncipes, mas sim, uma espécie de conselho para a ação do príncipe conquistador. Skinner (1996, p. 139) aponta algo semelhante.

${ }^{4}$ No Capítulo II, Maquiavel diz que tratará apenas dos principados e que em outra ocasião tratou longamente sobre as repúblicas (MAQUIAVEL, 1996, p. 5).

${ }^{5}$ Ernst Cassirer (2003, p. 185) diz que a palavra "dever" - no sentido de uma possível lista de atribuições morais destinada ao príncipe - parece difícil de ser encontrada na obra.

${ }^{6}$ A posição de Maquiavel é contrária a uma posição normativa, primeiro porque Maquiavel reconhece a presença da contingência no cenário político, o que ele vem a chamar, de certo modo, de fortuna, o qual ele associa características como ocasião, volúvel e instável (1996, pp.25-28); e, segundo porque, embora Maquiavel esteja fazendo uma descrição dos principados e de formas de conservá-los, há na obra um espírito de "political advice" como já destacou Mansfield.

7 Leo Strauss (1984) de modo distinto de Mansfield (political advice) vê, O Príncipe, de uma perspectiva de um tratado que: "[...] teaching is partly theoretical (knowledge of the nature of princes) and partly practical (knowledge of the rules with which the prince must comply)" (p.55). Aranha (2002) diz: "Não o preocupa saber como 'deveria ser' o governo ou o governante ideal. Interessa, isso sim, analisar como os homens governam; qual o limite ao uso da violência para conquistar ou conservar o poder [...] (p. 41).

${ }^{8}$ Sobre o seu método, Maquiavel (1996) diz: "[...] o conhecimento das ações dos grandes homens, que aprendi através de uma longa experiência das coisas modernas e um contínuo estudo das antigas (p. 129).

${ }^{9}$ Cf. CABRINI (2010) e SKINNER (2000). 
A Itália de Maquiavel $^{10}$ sofria, por um lado, com a derrocada e conquista de novos principados e repúblicas e, por outro, com a falta de virtù dos príncipes italianos. No entanto, apesar de Maquiavel falar dos principados hereditários no início do livro, são, na verdade, os principados novos seu maior interesse ${ }^{11}$. Sobre os principados e o contexto político da Itália, Maquiavel ressalta o papel do agir político dos príncipes:

Considerando aqueles senhores que, na Itália, em nossos tempos perderam seus estados - como o rei de Nápoles, o duque de Milão e outros -, encontramos neles, primeiro, um erro comum quanto aos exércitos [...] E, depois, [...] alguns dentre eles ou tiveram o povo como inimigo ou, mesmo contando com a amizade do povo, não souberam conter os grandes (1996, pp.117-118).

De certo modo, Maquiavel reconhece que o contexto de derrocada e conquista de novos principados e, consequentemente, de enfraquecimento da própria Itália, estava ligado à indolência dos próprios príncipes (MAQUIAVEL, 1996, pp. 23-35). Indolência que se refletia no despreparo do exército e na lida com o povo e nobres, por um lado, e por outro, com a presença ou ausência da fortuna e da virtù. Sobre a presença ou ausência da fortuna e virtù - o que nos interessará no texto - Maquiavel no Capítulo XXIV, diz: "[...] nossos príncipes que tiveram por muitos anos o seu principado, que não acusem a fortuna por tê-lo perdido, mas a sua própria indolência por não terem jamais, em épocas de paz, pensado que os tempos poderiam mudar" (1996, p.118). Esta indolência, para Maquiavel, era um reflexo da falta de virtù dos príncipes.

Maquiavel acreditava que, "as defesas só são boas, seguras e duráveis quando dependem de ti mesmo e de tua virtù" (1996, p.118) ${ }^{12}$. Um príncipe dotado de virtù seria, nesse sentido, aquele capaz de agir de forma autônoma. A ideia de um homem autônomo que age por si próprio, segundo Bignotto (1991, pp.32-38), indica alguma herança da renascença humanista em Maquiavel ${ }^{13}$. Assim, de acordo com Ames e Skinner ${ }^{14}$ :

\footnotetext{
${ }^{10}$ A Itália de Maquiavel era formada por principados (governo aristocrático hereditário) e repúblicas (baseada na representatividade e na constituição de leis). Alguns dos principados italianos eram Nápoles, Ducado de Ferrara, Ducado de Milão e Marquesado de Montferrat e algumas das repúblicas eram Veneza, Florença e Luca (ARANHA, 2006, p. 23).

${ }^{11}$ E, em especial, a figura do príncipe conquistador (BIGNOTTO, 1991, p. 125).

${ }^{12}$ No Capítulo VI, Maquiavel diz: “[...] nos principados completamente novos, onde há um novo príncipe, existe maior ou menor dificuldade para mantê-lo conforme seja maior ou menor a virtù de quem o conquistou" (1996, p. 23).

${ }^{13}$ Quentin Skinner (1996) e Newton Bignotto (2008) apontam para o fato de que Maquiavel incorporou o "gênero literário dos espelhos dos príncipes" (1996, p. 149), mas criticandoo. Bignotto diz que Maquiavel "contraria as ideias difundidas pelos espelhos, que faziam do governante seguidor dos valores cristãos, em todas as suas configurações, o governante ideal" (2008, p. 81).
} 
Virtù é empregada por Maquiavel para indicar todo aquele complexo de aptidões que permitem a certos homens destacarse sobre a mediocridade geral e impor às coisas o rumo por eles decidido. É a capacidade de impor-se ao que é indeterminado e tenebroso na vida, evidenciando, desse modo, o poder e a autonomia do homem (AMES, 2002, p.138).

Para Maquiavel, [...], o conceito de virtù serve dessa forma para indicar a qualidade indispensável que capacita um príncipe a vencer as pedras e setas da enfurecida Fortuna, e a aspirar assim à obtenção da honra, glória, e fama (SKINNER, 1996, p. 142).

Em Maquiavel, virtù é diferente, em parte, da virtude cristã ${ }^{15}$, a qual "sujeitava o indivíduo à vontade divina" (AMES, 2002, p.139). Para Maquiavel, há um distanciamento ${ }^{16}$ teórico e prático entre moral e política no seio da ação dos príncipes. A tradição filosófica no campo moral era dominada pela tradição filosófico-cristã que pensava o ato de governar como a capacidade de realizar ações justas e boas. Esta tradição identificava na política e na expressão das virtudes (como, por exemplo, na filosofia de Platão e Agostinho) que governar era, essencialmente, um ato para o qual poucos estariam capacitados. Maquiavel se afasta dessa tradição e, sobretudo, da tradição medievalista (fortemente influenciada pela tradição moral-cristã) ao se distanciar da ideia de que as ações políticas seriam amparadas em ações morais. Entretanto, Maquiavel não nega a moral e sua importância na fundamentação dos costumes e das leis ${ }^{17} \mathrm{e}$, sim, a capacidade da moral de fundamentar as ações políticas dos príncipes.

Por outro lado, ao se distanciar dessa tradição moral (sobretudo, cristã), Maquiavel apresenta em relação aos principados novos, ditados pela lógica da conquista-conservação, uma nova concepção sobre o papel da

${ }^{14}$ Sobre uma definição mais ampla do conceito 'virtù', conferir, Mansfield (1996, pp.6-52).

${ }^{15}$ Mansfield (1996, p. 24) indica que há uma diferença moral entre virtù e bontà (ou bondade). Uma ação de virtù não visa necessariamente uma ação de bondade tal como é descrita pela tradição cristã.

${ }^{16}$ Este distanciamento está relacionado à "mudança na concepção da natureza humana" (BIGNOTTO, 1991, p. 53). No artigo, A antropologia negativa de Maquiavel, Bignotto (2008) reitera que, Maquiavel dá indícios de uma natureza humana que contempla à maldade humana, o que o leva diretamente a entrar em conflito com a tradição cristã. Embora, na tradição medievalista já se apontara para o fato da presença do pecado na natureza humana (pp. 80-81). Maquiavel, no Capítulo XVII, também aponta algumas características sobre a natureza dos homens: "são ingratos, volúveis, simulados e dissimulados, fogem dos perigos, são ávidos de ganhar [...]” (1996, p. 80).

${ }^{17}$ Ames (2002) aponta para dois modos distintos da realização política da religião para Maquiavel: "por um lado, a religião é um instrumento político, um meio pelo qual o governante prudente pode realizar, em nome de Deus, coisas extraordinárias e inabituais indispensáveis à continuidade no tempo do domínio político; de outro lado, porém, ela é também a vida profunda de um povo, seus bons costumes e sua educação política e moral" (p. 198). 
força na política e como que esta força está dissociada de prerrogativas morais. Além disso, com o contexto de fragilidade e instabilidade política da italiana, Maquiavel "se pergunta a respeito do segredo da força e da estabilidade dos Estados" (ARANHA, 2006, p. 48). Neste contexto de conflito $^{18}$ é possível dizer que o problema da força (sobretudo, expresso na lógica da conquista-conservação e fundação-conservação) torna-se um objeto de análise indireto da política dos príncipes para Maquiavel.

\title{
Problema da Força: conquista-conservação e fundação-conservação
}

Após classificar em duas formas políticas os regimes políticos, Maquiavel divide os principados em dois tipos:

\begin{abstract}
Os principados ou são hereditários - nos quais o sangue de seu senhor vem governando há longo tempo - ou são novos. Os novos ou são inteiramente novos, como Milão sob Francesco Sforza, ou são membros anexos ao estado hereditário do príncipe que os adquire (1996, p. 3).
\end{abstract}

A conservação dos principados hereditários, em grande medida, estava amparada na manutenção ${ }^{19}$ dos costumes e das leis. Assim, conforme aponta Maquiavel, "basta não descuidar da ordem instituída pelos seus antepassados e, depois, saber contemporizar os acidentes" (1996, p. 5) para que houvesse estabilidade. Já nos principados novos, Maquiavel reconhece algumas dificuldades inerentes à sua conservação, como por exemplo: alguns destes principados não eram completamente novos, mas membros anexos de outros e, portanto, com um corpo social e político já bem estabelecido; outros principados novos eram acostumados à liberdade e ao julgo de suas próprias leis e costumes, o que dificultava a inserção de novos costumes e leis; e, por fim, alguns principados novos foram, em grande medida, conquistados exclusivamente sob o julgo da força ou da virtù ou da fortuna, o que impedia, em parte, o seu reconhecimento pelo povoconquistado.

Diante desse cenário de conquista de principados civis, Maquiavel estuda o ato da conquista a partir de alguns casos de conquistadores particulares (BIGNOTTO, 1991, p. 125); e observa que o ato da conquista é, na verdade, um ato político e não meramente um ato de força. Trata-se de

\footnotetext{
${ }^{18}$ Segundo Ames, um contexto em que o conflito é essencialmente político (2013, p. 98).

${ }^{19}$ Contudo, Maquiavel dá o exemplo da conquista de Milão por Luís XII. Em principados mistos apenas a conservação de velhos costumes e leis não é suficiente para garantir a estabilidade (1996, pp.8-9). É necessário extinguir o sangue do antigo príncipe e não alterar suas leis e impostos (ibidem). Extinguir o sangue do antigo príncipe está também relacionado ao fato de reconhecer que "aos homens é natural e comum o desejo da conquista" (ibidem, p.14). Bignotto reitera essa questão da seguinte forma: "A estabilidade, atributo dos principados hereditários, não pode ser vista como uma garantia contra a conquista" (1991, p. 124).
} 
um ato político que é marcado por diferentes usos da força como atividade política, dentre eles, por exemplo: pela força das armas, pela força da destruição ou conservação simbólica de um povo e pelo embate ou incorporação de um corpo político e social. Por isso, Maquiavel, segundo Bignotto:

Combate os jovens de seu tempo, que viam na força o único elemento motriz da política, mostrando que nem mesmo uma conquista levada a cabo pela força das armas se esgota no momento da invasão. [...] Devemos, pois, distinguir a conquista - momento da pura negatividade - da fundação - momento de criação social (1991, p. 127).

No ato político da conquista, a força, como um ato de violência, está inevitavelmente presente. Maquiavel, entretanto, parece se interessar no Príncipe não pela força como violência, mas pela força como atividade política $^{20}$. No Príncipe, a força como atividade política justificaria o agir político, amparado na ideia de que a força seria um elemento complexo, com diferentes possibilidades de uso político, e que seria, sobretudo, um elemento mediador entre a política e a pura violência.

Assim, podemos dizer que no ato da conquista-conservação a força está presente, inicialmente, como desejo da conquista. Para Maquiavel isto se traduz nos seguintes termos: "é, de fato, muito natural e comum o desejo de conquistar" (1996, p.14). Esta afirmação de Maquiavel é importante porque assinala para o fato de que, não só o ato da conquista, mas a própria conservação, é permeada pelo desejo da conquista. É por isso que nos principados hereditários a manutenção dos costumes e das leis não é condição suficiente para garantir sua estabilidade. Devemos, então, entender que o que Maquiavel diz com "muito natural" não se refere a uma descrição antropológica do homem, mas apenas evidencia uma perspectiva histórica da recorrência do ato e do desejo da conquista.

Força, nesse cenário inicial de "desejo da conquista", é uma força interna e externa ao ato da conquista. Interna porque é natural o seu desejo (sendo a conquista realizada por armas, fortuna ou virtù ${ }^{21}$, mas também é externa, porque o ato da conservação tem de conviver incessantemente com esse desejo natural e, ao mesmo tempo, combatê- $10^{22}$. Nesse sentido, Maquiavel parece entender a força não de uma perspectiva ontológica, ou

\footnotetext{
${ }^{20}$ Segundo Ames (2002): "Principados novos são aqueles conquistados pela ação de homens de virtù no decurso de um processo de luta. $\mathrm{O}$ conquistador, que num primeiro momento é apenas um destruidor que impõe pela força a lei, passa num momento seguinte à condição de fundador, isto é, da pura negatividade passa para a posição de criador [...]" (p. 178).

${ }^{21}$ Do Capítulo III ao IX, Maquiavel aponta as formas de conquistas possíveis dos principados e, especialmente, destaca os principados conquistados pelas armas, fortuna e virtù.

${ }^{22}$ Bignotto (2008), diz que há "duas ordens naturais a presidir o momento da conquista" (p.83): a natureza humana volátil e o poder do príncipe novo.
} 
antropológica, mas apenas tenta compreendê-la como um problema político para a conquista e conservação de novos principados.

Por conseguinte, podemos dizer que na conquista-conservação, a força também está presente como ato da conservação. Nesse momento, o desafio do príncipe é a inovação (BIGNOTTO, 1991, p. 125). A inovação presente no constante desejo de mudança torna o ato de conservação um ato de negociação. Por isso, na conquista-conservação sempre há aqueles que ganham e aqueles que perdem. O príncipe conquistador ao "introduzir uma nova ordem, tem por inimigos todos aqueles que se beneficiam com a antiga ordem, e como tímidos defensores todos aqueles a quem as novas instituições beneficiariam" (MAQUIAVEL, 1991, p. 25). A balança do príncipe conquistador, neste contexto, dificilmente se equilibra em principados novos, sobretudo, aqueles mistos. Com relação a estes principados (de natureza civil), acostumados a viver sob o julgo de suas próprias leis, Maquiavel diz que há somente três maneiras de conservá-los:

A primeira é destruí-los, a outra é ir pessoalmente residir neles, e a terceira é deixá-los viver sob suas próprias leis, impondolhes um tributo e criando dentro deles um governo de poucos, que se conserve seu amigo (1996, p.21).

Embora nesses principados ou cidades Maquiavel apresente três alternativas, ele mesmo acredita que assim como aconteceu com Atenas, Tebas, Cápua, Cartago e Numância, é necessário, na verdade, destruí-los ${ }^{23}$ (precisamente, destruir os privilégios hereditários e, consequentemente, as antigas instituições). Para Maquiavel, este seria o único meio seguro de conservá-los; caso contrário, se as leis fossem mantidas nesses principados ou cidades, haveria sempre enraizado no corpo social, um espírito de rebelião que em "nome de sua liberdade e de sua antiga ordem" (MAQUIAVEL, 1991, p. 22) sempre se levantaria contra o príncipe conquistador.

Assim, se em um primeiro momento há uma dissolução do corpo político e social no ato da conquista, em um segundo momento há um ato positivo de criação que faz com que "o conquistador vitorioso passe, numa fração de segundos, da pura negatividade para a posição de criador" (BIGNOTTO, 1991, p.127). Este ato de criação, que é o ponto intermediário entre a conquista e a conservação, é a fundação. $O$ ato da fundação é por si só um ato de força (embora nem toda fundação seja uma resultante do uso da força [BIGNOTTO, 1991, p. 127]). Na fundação, assim como na conquista, a força como atividade política dos príncipes também se apresenta de diferentes modos e com diferentes usos.

O primeiro modo ou momento, pode-se dizer, é a exterioridade do príncipe. O príncipe conquistador que se torna o príncipe novo, ao mesmo

${ }^{23} \mathrm{E}$ aos destruí-los, o príncipe conquistador, toma pra si, o próprio ato de criação. 
tempo, é aquele que conquista e cria. No ato da conquista, "o conquistador, num primeiro momento, é apenas um destruidor que quer impor sua lei" (BIGNOTTO, 1991, p. 126), sendo assim, aquele que é exterior ao principado. Esta exterioridade se mescla com o fato de que o ato da fundação pelo príncipe é o desejo de um (BIGNOTTO, 1991, p. 127). Nesse sentido, como reitera Bignotto: "se a fundação é obra de um só - o príncipe novo - não pode ser eficaz se não escapar da lógica da pura força” (1991, 0. 132).

O segundo momento da fundação nesses principados civis, ou seja,"a passagem de simples cidadão a príncipe" (MAQUIAVEL, 1996, p. 23), obriga o príncipe conquistador a superar a sua imagem de pura força exterior e vontade de um e a assumir a tarefa de fundador. Assim, "a fundação é a combinação entre o gesto de força do príncipe [...] e a adesão às novas instituições" (BIGNOTTO, 1991, p. 132). Maquiavel, sobre esse momento de fundação-conservação, diz que:

As dificuldades que têm para conquistá-los nascem em parte da nova ordem e dos novos métodos que são obrigados a introduzir para fundar o seu estado e a sua segurança. Devemos convir que não há coisa mais difícil de se fazer, mais duvidosa de se alcançar, ou mais perigosa de se manejar do que ser o introdutor de uma nova ordem [...] (1991, p. 25).

A inovação é o grande desafio do príncipe e o príncipe inovador é o desafio do principado. O que se julga de um príncipe, nesse sentido, é que se como príncipe inovador ele dispõe "de meios próprios ou depende de outros, isto é, se para realizar a sua obra precisa pedir ou pode forçar" (MAQUIAVEL, 1991, p. 25). Se o príncipe precisa pedir, então dificilmente, como aponta Maquiavel, terá ele sucesso, mas se dispõe de próprios meios e pode usar da força, então raramente fracassa:

[...] a natureza dos povos é variável; e, se é fácil persuadi-los de uma coisa, é difícil firmá-los naquela convicção. Por isso, convém estar organizado de modo que, quando não acreditarem mais, seja possível fazê-los crer à força (MAQUIAVEL, 19991, pp. 25-26).

O príncipe pode "fazê-los crer à força" de diferentes modos, isto é, pode, no ato da fundação, se utilizar de diferentes formas do uso da força para assegurar a conservação do novo regime. Dentre essas formas, pode o príncipe fazer com que creiam (na nova instituição e em sua autoridade, por exemplo) não apenas pelo uso prático da força, mas também pelo seu uso simbólico. Sobre o uso simbólico da força, Maquiavel, no Capítulo XVII, diz, por exemplo, que é melhor ser temido do que amado e é melhor ser piedoso do que considerado cruel (1991, p. 80); e, reitera que: “[...] o príncipe fazer-se temer de modo que, se não conquistar o amor, pelo menos 
evitará o ódio; pois é perfeitamente possível ser temido e não ser odiado ao mesmo tempo" (1991, pp.80-81).

O uso simbólico da força nesse contexto de fundação-conservação é um exercício de virtude. Por isso, nas passagens acima, Maquiavel parece apenas apontar algumas características da virtù que o príncipe novo deveria seguir e não parece ter a intenção de fazer uma defesa de ações desmedidas (ou imorais), tal como, a tradição o interpretou ${ }^{24}$. Na verdade, Maquiavel parece dar uma justificativa prática das ações dos príncipes, amparada na manutenção e conservação dos principados. Essas ações visariam um equilíbrio, algo que é próprio da virtù dos grandes príncipes ${ }^{25}$.

A ideia de justificativa parece mais clara na seguinte passagem: "Se precisar derramar o sangue de alguém, deverá fazê-lo quando houver justificativa conveniente e causa manifesta" (MAQUIAVEL, 1991, p. 81, grifo nosso). O que parece implícito aqui é que a justificativa seria de ordem política, assim como a força utilizada (força prática ou simbólica), mas ambas não estariam, em certo sentido, dissociadas da moral (como ações desmedidas), nem dissociadas de um bem comum. Isto porque Maquiavel reconhece que é preciso satisfazer "antes o povo do que os soldados, porque o povo é quem tem mais poder" (MAQUIAVEL, 1996, p. 97). Nesse sentido, o príncipe que usa a força como instrumento político não deve se esquecer de que "um príncipe deve valorizar os grandes mas não se fazer odiar pelo povo" (MAQUIAVEL, 1996, p. 91). Ter o povo sempre ao lado do príncipe é, para Maquiavel, um instrumento de conservação e, invariavelmente, de força. Maquiavel diz:

Concluo, portanto, que um príncipe deve ter em pouca conta as conspirações enquanto o povo lhe for favorável, mas, quando este se tornar seu inimigo ou lhe tiver ódio, deverá temer todas as coisas e todo mundo. Os estados organizados e os príncipes sábios têm aplicado toda diligência tanto em não exasperar os grandes como em satisfazer o povo e fazê-lo contente, porque está é uma das principais funções que cabem a um príncipe (1996, p. 90).

O príncipe conquistador de Maquiavel, em síntese, é um príncipe de ação que, ao reconhecer a política como um campo de conflitos constantes, percebe que sobreviver neste contexto de conflito é, na verdade, um exercício de virtù. Nesse cenário, portanto, a força (como atividade política) torna-se também uma atividade da virtù dos príncipes.

\footnotetext{
${ }^{24}$ Aranha (2006), diz que: "Na linguagem comum costumamos chamar de maquiavélicas as pessoas cínicas, ardilosas, traiçoeiras, que, para atingir fins inconfessáveis, usam de mentira e má-fé [...] Em política, a máxima atribuída a Maquiavel - “os fins justificam os meios" -, desligada do seu contexto parece privilegiar exclusivamente a eficácia da ação em detrimento da valorização da conduta moral" (p. 7).

${ }^{25}$ Conforme Maquiavel destaca no Capítulo VI, ao chamar Moisés, Ciro, Rômulo e Teseu de príncipes.
} 


\section{Considerações Finais}

Quando se tem um olhar mais cuidadoso para as ações dos príncipes, observa-se que Maquiavel está, na verdade, exaltando no seio da ação política dos príncipes a natureza dos homens e de sua virtù. Essas ações visam à conservação e defesa dos novos principados, por um lado, mas também o bem comum do povo, por outro. Por isso, o príncipe conquistador é aquele que, em certa medida, negocia com o povo, com o exército, com seus pares, mas sempre tendo em vista a sua posição privilegiada como ser de ação e criação. Portanto, a política descrita no Príncipe é uma política fundada em ações que reconhecem a constante presença do conflito e, por isso, a questão da força, no cenário de conquista-conservação e de fundaçãoconservação em Maquiavel, se apresenta como uma questão de natureza política, justificada, sobretudo, pelo uso que o príncipe conquistador faz de suas possibilidades políticas. A virtù, neste uso, é a própria atividade política do príncipe.

\section{Referências bibliográficas}

AMES, J, Luiz. Maquiavel: A Lógica da Ação Política. Cascavel: EDUNIOESTE, 2002.

Função do Conflito sob um Governo Principesco: Poder Político

e Jogo de Alianças em Maquiavel. In: Filosofia Política no Renascimento Italiano. Org. Helton Adverse. São Paulo: Annablume, 2013, pp.97-144.

ARANHA, M, L. Maquiavel: A lógica da força. 2. ed. São Paulo: Moderna, 2006.

BIGNOTTO, N. Maquiavel Republicano. São Paulo: Loyola, 1991.

A Antropologia Negativa de Maquiavel. Revista Analytica, Rio de Janeiro, vol $12 \mathrm{n}^{\circ}$ 2, 2008, p.77-100.

CABRINI, A, Maria. Machiavelli's Florentine Histories. In: The Cambridge

Companion to Machiavelli. Ed. John M, Najemy. Cambridge: Cambridge University Press, 2010, pp. 128-143.

CASSIRER, Ernst. O mito do estado. São Paulo: Codex, 2003. pp.145-195. CHEVALLIER, Jean-Jacques. As grandes obras políticas: de Maquiavel a nossos dias. 3a ed. Rio de Janeiro: Agir, 1986. pp.11-49.

MANSFIELD, H. Machiavelli's Virtue. Chicago: Chicago University Press, 1995.

MAQUIAVEL, N. O Príncipe. 2. ed. Trad. Maria Júlia Goldwasser. São Paulo: Martins Fontes, 1996.

SKINNER, Q. Machiavelli: A very short introduction. Oxford: Oxford UniversityPress, 1981. . As fundações do Pensamento Político Moderno. Trad. Renato J.

Ribeiro e Laura T. Motta. São Paulo: Companhia das Letras, 1996. 
STRAUSS, Leo. Thoughts on Machiavelli. Chicago: Chicago University Press, 1984. 